\title{
CLOZAPINE-INDUCED DIABETIC KETOACIDOSIS: A CASE REPORT
}

\author{
SOUMYA MARY ALEX ${ }^{1 *}$, VIDYA P MENON ${ }^{2}$, SABARISH $^{3}{ }^{3}$, UMADEVI $^{1}$, DIPU T $^{2}$
}

${ }^{1}$ Department of Clinical Pharmacy, Amrita Institute of Medical Sciences and Research Centre, Amrita Vishwa Vidyapeetham, AIMS Health Sciences Campus, Kochi, Kerala, India. ${ }^{2}$ Department of Medicine/Medical Administration, Amrita Institute of Medical Sciences and Research Centre, Amrita Vishwa Vidyapeetham, AIMS Health Sciences Campus, Kochi, Kerala, India. ${ }^{3}$ Department of Emergency Medicine and Critical Care, Amrita Institute of Medical Sciences and Research Centre, Amrita Vishwa Vidyapeetham, AIMS Health Sciences Campus, Kochi, Kerala, India. Email: soumyama21152@aims.amrita.edu

Received: 13 April 2017, Revised and Accepted: 01 December 2017

\section{ABSTRACT}

The objective of this study was to report a case of a person with psychiatric illness treated with clozapine presented with diabetic ketoacidosis (DKA). A clinical monitoring was done on a 38-year-old Indian man affected by schizoaffective disorder, bipolar type presented with DKA after 3 months of clozapine therapy ( $250 \mathrm{mg} /$ day). After treatment of DKA and discontinuation of clozapine, the patient improved symptomatically, his blood sugar levels normalized and insulin requirements also decreased. This report thus highlights that clinicians should be vigilant about the potential risk of new-onset diabetes and DKA in patients taking clozapine and utilize appropriate clinical and laboratory monitoring early in the course of treatment to prevent serious adverse effects.

Keywords: Clozapine, Diabetic ketoacidosis, Type 2 diabetes, Antipsychotic.

(C) 2018 The Authors. Published by Innovare Academic Sciences Pvt Ltd. This is an open access article under the CC BY license (http://creativecommons. org/licenses/by/4. 0/) DOI: http://dx.doi.org/10.22159/ajpcr.2018.v11i3.19140

\section{INTRODUCTION}

Clozapine is an atypical antipsychotic indicated for the management of treatment-resistant schizophrenia and to reduce the suicidal behavior in patients with schizophrenia or schizoaffective disorder. Hyperglycemia, in some cases associated with ketoacidosis or hyperosmolar coma or death, has been reported in patients treated with atypical antipsychotics including clozapine [1-5]. This is the case report of a man affected by schizoaffective disorder, bipolar type who developed Type 2 diabetes mellitus and diabetic ketoacidosis (DKA) while on clozapine for a duration of 3 months, but in our case, it was noted that even after adequate glycemic control, the acidosis took a relatively longer period to normalize.

\section{METHODOLOGY}

Informed consent was taken as per the institutional policy.

\section{CASE REPORT}

A 38-year-old man of Indian descent affected by schizoaffective disorder, bipolar type was admitted with complaints of vomiting, headache, and fever for 4 days. Initially, the patient was admitted in a local hospital where his blood sugar was $>600 \mathrm{mg} / \mathrm{dl}$ and managed with insulin infusion and referred to AIMS. This patient had a history of psychiatric illness for nearly 20 years and was on and off medications for the same. The patient was started on clozapine therapy before 3 months considering the severity of his psychotic symptoms and suicidal ideation. On initiation of therapy, his random serum glucose level was $111.9 \mathrm{mg} / \mathrm{dL}$.

At the time of admission to our center, his random glucose was $378 \mathrm{mg} / \mathrm{dl}$. However, his acidosis persisted. He was dehydrated and laboratory data revealed his glycosylated hemoglobin was $14 \%$. Arterial blood gases showed $\mathrm{pH} 7.15, \mathrm{pCO}_{2} 17.3 \mathrm{mmHg}, \mathrm{pO}_{2} 121 \mathrm{mmHg}$, and bicarbonate $9.8 \mathrm{mmol} / \mathrm{L}$. Serum and urinary ketones were positive. Routine blood investigations revealed normal counts with mild elevation of serum creatinine $(1.54 \mathrm{mg} / \mathrm{dL})$ and C-reactive protein $(18.6 \mathrm{mg} / \mathrm{L})$. Serum sodium and potassium levels at admission were $134.4 \mathrm{mmol} / \mathrm{L}$ and
$4.2 \mathrm{mmol} / \mathrm{L}$, respectively. He was managed with intravenous potassium infusions to maintain target serum K+levels as per DKA protocol. His detailed arterial blood gas values for 3 days are represented in Table 1. Computed tomography scan of the brain was normal. Toxicological analysis of urine, blood, and gastric aspirate was done. The urine sample was positive for clozapine. Clozapine was discontinued. Over the next 3 days, the patient improved symptomatically, his blood sugar levels normalized and insulin requirements also decreased. His acidosis and anion gap took $72 \mathrm{~h}$ to normalize. Following this, a psychiatric consultation was taken and aripiprazole was initiated. The patient was discharged after 12 days on a diabetic diet, metformin, human insulin, and isophane insulin. At the time of discharge, his serum glucose level was $134 \mathrm{mg} / \mathrm{dL}$. The patient came for review after 1 week of discharge and his fasting blood sugar was 69.7 and post prandial blood sugar (PPBS) was $175 \mathrm{mg} / \mathrm{dL}$. His insulin requirement decreased to biphasic isophane insulin.

\section{DISCUSSION}

Atypical antipsychotics have demonstrated a significant advantage over conventional antipsychotics not only in terms of clinical efficacy but also safety, with lower incidence of extrapyramidal symptoms and tardive dyskinesia. However, there have been numerous case reports, epidemiological data suggesting that certain atypical antipsychotics may be associated with a greater risk of metabolic abnormalities than others including weight gain, hyperlipidemia, and new onset Type 2 diabetes mellitus or DKA [6]. Among atypical antipsychotics currently in use, clozapine and olanzapine are known to have the highest risk of metabolic complications $[2,3]$.

DKA, an acute metabolic complication of diabetes, although appears to be uncommon, is of great concern secondary to the risk of death. The incidence of diabetes presenting as DKA in schizophrenia patients is almost 10-fold higher than that reported in the general population [3].

The risk factors for the development of DKA during clozapine treatment are unclear since clozapine treatment has been associated with DKA even in patients with no documented history of hyperglycemia, 
Table 1: Arterial blood gas values during the DKA period ( $1^{\text {st }} 3$ days)

\begin{tabular}{|c|c|c|c|c|c|c|c|c|c|}
\hline \multirow{2}{*}{$\begin{array}{l}\text { Values } \\
\text { Plasma glucose }(\mathrm{mg} / \mathrm{dL})\end{array}$} & \multicolumn{5}{|l|}{ Day1 } & \multicolumn{2}{|l|}{ Day 2} & \multicolumn{2}{|c|}{ Day 3} \\
\hline & 187 & 225 & 207 & 189 & 149 & 171 & 208 & 147 & 94 \\
\hline Arterial pH & 7.16 & 7.14 & 7.14 & 7.19 & 7.17 & 7.21 & 7.26 & 7.34 & 7.34 \\
\hline Serum bicarbonate $(\mathrm{mmol} / \mathrm{L})$ & 10.7 & 10.3 & 9.3 & 11.8 & 10.7 & 12.8 & 13.9 & 18.2 & 17.9 \\
\hline Lactate $(\mathrm{mmol} / \mathrm{L})$ & 0.6 & 0.6 & 0.8 & 0.6 & 0.5 & 0.6 & 0.7 & 0.8 & 0.6 \\
\hline PCO2 (mmHg) & 21.4 & 21.3 & 18.5 & 24.1 & 22.8 & 28.7 & 25.3 & 29.5 & 30.8 \\
\hline
\end{tabular}

DKA: Diabetic ketoacidosis

diabetes, or weight gain. However, people of African American or African Caribbean descent have been reported to be more susceptible to this adverse effect $[2,4,7,8]$. In our case, apart from a family history of diabetes, the patient had no other predisposing factor. He had no weight gain during treatment; hence, this cannot be implicated in the onset of DKA.

DKA has been reported to typically occur early in the course of treatment, with high proportion of patients developing it within 3 months of clozapine initiation [4,9-11]. In our case also, it took nearly 3 months before a diagnosis of ketoacidosis was made. However, elevated glycosylated hemoglobin levels observed at admission suggest that the patient had impaired glucose tolerance for at least several weeks before the DKA episode.

The association between clozapine and DKA does not appear to be dose dependent. In the reported cases of DKA, among clozapinetreated patients, clozapine doses have ranged from $150 \mathrm{mg} /$ day to $500 \mathrm{mg}$ /day $[7,9,11]$. Our patient developed DKA while taking $250 \mathrm{mg} /$ day of clozapine for 3 months.

Assessment of the relationship between atypical antipsychotic use and glucose abnormalities is complicated by the possibility of an increased background risk of diabetes mellitus in patients with schizophrenia. However, the occurrence of cases of new or worsening diabetes mellitus and DKA in patients using clozapine suggests a causal relationship. The mechanism by which clozapine causes diabetes and other metabolic disturbances are not fully understood but could involve insulin resistance, suppression of insulin release, or impairments in glucose utilization, leading to the development of abnormal glucose tolerance, which can be clinically manifested as a spectrum ranging from impaired glucose tolerance through severe hyperglycemia to DKA [12].

Reports and clinical experience suggest that in a case of clozapineassociated diabetes or DKA, discontinuation of the drug may result in resolution of the hyperglycemia and diabetes $[7,9,11]$. Consistent with the same, in our patient, after supportive treatment involving discontinuation of medication and intensive glycemic control, the metabolic parameters and clinical symptoms were restored in a short time, indicating that the effects of clozapine-induced metabolic complications are reversible. However, in our case, it was also noted that even after adequate glycemic control, the acidosis took a relatively longer period to normalize.

\section{CONCLUSION}

Clozapine-related DKA can occur soon after treatment and can persist several days, irrespective of ethnic origin, in the absence of family history of diabetes or weight gain, and does not also appear to be dose dependent. The $1^{\text {st }} 3-6$ months of clozapine treatment appear to be a high-risk period. Although the occurrence of DKA is rare, in our case, it persisted 3 days. Clinicians must remain vigilant given its acute onset and potential lethality and should utilize appropriate clinical and laboratory monitoring early in the course of treatment to prevent serious adverse effects as discontinuation of the drug is of paramount importance in management.

\section{AUTHOR'S CONTRIBUTIONS}

Soumya Mary Alex: Interpretation of data, drafting of report and approval of the version to be published. Dr. Dipu T.S: Interpretation of data, drafting of report and approval of the version to be published. Dr. Sabarish B: Interpretation of data, revising of report for important intellectual content and approval of the version to be published. Dr. Uma Devi P: Interpretation of data, drafting of report and approval of the version to be published. Dr. Vidya P Menon: Interpretation of data, revising of report for important intellectual content and approval of the version to be published.

\section{CONFLICTS OF INTEREST}

None.

\section{REFERENCES}

1. US Prescribing Information of CLOZARIL ${ }^{\circledR}$ (clozapine) Tablets, for Oral Use;2014.Availablefrom:https://www.pharma.us.novartis.com/ product/pi/pdf/Clozaril.pdf. [Last accessed on 2014 Sep ].

2. Jin H, Meyer JM, Jeste DV. Phenomenology of and risk factors for new-onset diabetes mellitus and diabetic ketoacidosis associated with atypical antipsychotics: An analysis of 45 published cases. Ann Clin Psychiatry 2002;14:59-64.

3. Henderson DC, Cagliero E, Copeland PM, Louie PM, Borba CP, Fan X, et al. Elevated hemoglobin A1c as a possible indicator of diabetes mellitus and diabetic ketoacidosis in schizophrenia patients receiving atypical antipsychotics. J Clin Psychiatry 2007;68:533-41.

4. Nihalani ND, Tu X, Lamberti JS, Olson D, Olivares T, Costea GO, et al. Diabetic ketoacidosis among patients receiving clozapine: A case series and review of socio-demographic risk factors. Ann Clin Psychiatry 2007; 19:105-12.

5. Yadav M, Parle M, Kadian M, Sharma K. A review on psychosis and antipsychotic plants. Asian J Pharm Clin Res 2015;8:24-8.

6. Jin H, Meyer JM, Jeste DV. Atypical antipsychotics and glucose dysregulation: A systematic review. Schizophr Res 2004;71:195-212.

7. Ai D, Roper TA, Riley JA. Diabetic ketoacidosis and clozapine. Postgrad Med J 1998;74:493-4.

8. Vishnupriya R, Ezhilramya J, Meenakshi B. Metformmin in the prevention of metabolic syndrome associated with initiation of atypical antipsychotic therapy in adolescents and young adults-A randomized, open labelled, Single centered study. Int J Pharm Pharm Sci 2016;8:2006.

9. Kasmi Y. A case of clozapine induced diabetic ketoacidosis. Psychiatrist Online 2013;37:36.

10. Colli A, Cocciolo M, Francobandiera F, Rogantin F, Cattalini N. Diabetic ketoacidosis associated with clozapine treatment. Diabetes Care 1999;22:176-7.

11. Lafayette JM, Pirl WF, Henderson DC. Low-dose clozapine and diabetic ketoacidosis. Psychosomatics 2003;44:249-52.

12. Avram AM, Patel V, Taylor HC, Kirwan JP, Kalhan S. Euglycemic clamp study in clozapine-induced diabetic ketoacidosis. Ann Pharmacother 2001;35:1381-7. 